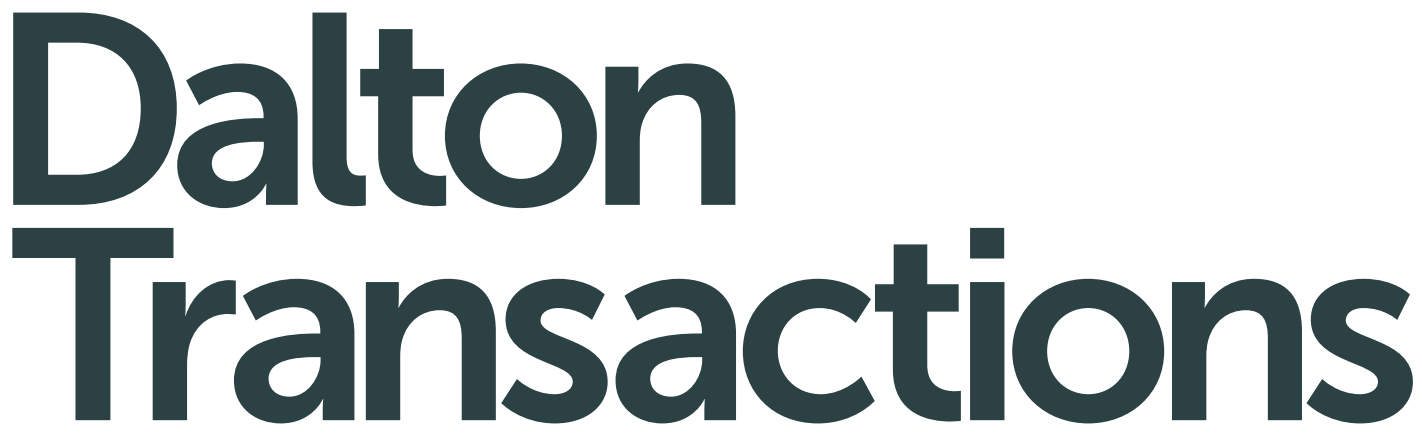

An international journal of inorganic chemistry rsc.li/dalton
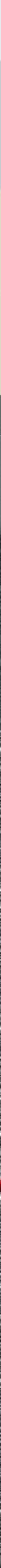

ISSN $1477-9226$

ROYAL SOCIETY | Celebrating OF CHEMISTRY IYPT 2019
PAPER

Goran Angelovski et al.

Investigations into the effects of linker length elongation on the behaviour of calcium-responsive MRI probes 


\section{(A) Check for updates}

Cite this: Dalton Trans., 2019, 48, 13546

\title{
Investigations into the effects of linker length elongation on the behaviour of calcium- responsive MRI probes $\uparrow$
}

\author{
Liam Connah, ${ }^{a}$ Vincent Truffault, ${ }^{\mathrm{b}}$ Carlos Platas-Iglesias (iD c ${ }^{\mathrm{c}}$ and \\ Goran Angelovski (D) *a
}

\begin{abstract}
Understanding the relationship between chemical structure and the effectiveness of bioresponsive magnetic resonance imaging (MRI) contrast agents can offer help to identify key components required for the future development of such probes. Here, we report the development and characterisation of two novel monomeric bifunctional chelators, $\mathbf{L}^{1}$ and $\mathbf{L}^{2}$, whose paramagnetic metal complexes can serve as calcium-responsive contrast agents. Specifically, relaxometric titrations, luminescence lifetime measurements, high resolution NMR and diffusion experiments, as well as density functional theory (DFT) calculations were carried out to assess the behaviour of each system. Minor structural differences between the probes resulted from the extension of the linker between the macrocyclic lanthanide chelator and the acyclic Ca-binding moiety. Relaxometric titrations of both systems, $\mathbf{G d L}^{1}$ and $\mathbf{G d L}^{2}$, showed an increase in $r_{1}$ and $r_{2}$ relaxivity upon $\mathrm{Ca}^{2+}$ addition, with the derivative bearing the longer linker showing a greater overall change. The hydration states of the europium analogues were assessed revealing a higher initial hydration state for EuL ${ }^{2}$. Diffusion ordered NMR spectroscopy revealed negligible changes in the diffusive properties of both systems upon the addition of $\mathrm{Ca}^{2+}$, while NMR studies of the $\mathrm{Y}^{3+}, \mathrm{Yb}^{3+}$ and $\mathrm{Eu}^{3+}$ analogues provided further insights into the structural behaviour of the linker unit in both the unsaturated and Ca-saturated states. DFT calculations supported the different coordination modes of the studied paramagnetic complexes in the presence and absence of $\mathrm{Ca}^{2+}$. Overall, our findings demonstrate the impact of subtle changes to the structure of such probes, affecting a range of properties and their coordination

behaviour.
\end{abstract}

Received 25th June 2019
Accepted 25th July 2019

DOI: $10.1039 /$ c9dt02672j

rsc.li/dalton

\section{Introduction}

Magnetic resonance imaging (MRI) is an essential diagnostic imaging technique used widely in clinics to provide three dimensional soft tissue images at high spatial resolution. In recent years, MRI has been a primary focus in the field of molecular imaging due to attempts to develop methods for the dynamic visualization of biological processes. ${ }^{1-4}$ The advancement of these so-called functional methods and the ability to monitor such changes can provide crucial information such as the function of tissues or organs in pathological states. Typically, MRI can be performed with or without the addition

\footnotetext{
${ }^{a}$ MR Neuroimaging Agents, Max Planck Institute for Biological Cybernetics, 72076 Tuebingen, Germany. E-mail: goran.angelovski@tuebingen.mpg.de ${ }^{b}$ Max Planck Institute for Developmental Biology, 72076 Tuebingen, Germany ${ }^{c}$ Centro de Investigacións Científicas Avanzadas (CICA) and Departamento de Química, Facultade de Ciencias, Universidade da Coruña, 15071 A Coruña, Spain $\dagger$ Electronic supplementary information (ESI) available: NMR, MS and luminescence lifetime experiments, DFT structures. See DOI: 10.1039/c9dt02672j
}

of a contrast agent (CA) unlike other imaging techniques. The inclusion of such a CA in MRI can provide greater specificity through the shortening of the $T_{1}$ and $T_{2}$ relaxation times of the protons in the immediate vicinity of the CA. Differing from conventional CAs, 'smart' or bioresponsive smart contrast agents (SCAs) are suitable for functional MRI (fMRI) studies and have been applied to monitor different environmental states as their MR properties fluctuate depending on their microenvironment. Many SCAs have been developed for a variety of functions including the monitoring of $\mathrm{pH}$, specific metal ions $\left(\mathrm{Ca}^{2+}, \mathrm{Zn}^{2+}\right)$ and enzymes. ${ }^{1,5,6}$ Typically, they are based on cyclen scaffolds complexed with paramagnetic ions, and possess protonable groups (i.e. $\mathrm{pH}$ sensors), an additional specific chelator for a desired analyte $\left(\right.$ e.g. $\left.\mathrm{Ca}^{2+}, \mathrm{Zn}^{2+}\right)$ or a moiety which can be affected by enzyme activity. ${ }^{7}$ As the mechanism of action, usually SCAs are either considered as 'off-on' or 'on-off' systems, meaning they alter their relaxometric properties to provide a significant difference between two different environmental states. ${ }^{5}$ One of the preferred targets is $\mathrm{Ca}^{2+}$ due to its significance in biological processes. ${ }^{8,9}$ 
These include a substantial involvement in critical cellular signalling events and an association with various pathologies including ischemia, Alzheimer's disease and epilepsy. ${ }^{10,11}$ Abilities to track $\mathrm{Ca}^{2+}$ fluctuations could prove useful in monitoring and understanding these pathological processes. Furthermore, due to the involvement of $\mathrm{Ca}^{2+}$ in neural activity, the development of $\mathrm{Ca}^{2+}$ sensing MRI probes could lead to the mapping of brain activity in a direct manner. Many attempts to develop Ca-responsive SCAs have been pursued over recent years resulting in the production of a variety of molecules ranging from smaller monomeric compounds to larger nanosized derivatives. ${ }^{3,12,13}$ The desire to understand the relationship between SCA structure and relaxometric enhancement has brought about a series of studies investigating such effects, thus providing significant insights into the behaviour of these systems. ${ }^{14,15}$ Specifically, the interaction of the carboxylates from the Ca-binding chelate with the paramagnetic metal ion or the roles of the two stereoisomers, square antiprismatic (SAP) and twisted square antiprismatic (TSAP), of 1,4,7,10-tetraazacyclododecane-1,4,7-tris(methylenecarboxylic) acid (DO3A) macrocyclic chelators have revealed interesting coordination properties of these responsive systems. Furthermore, the influence of the distance between the MR reporting and bioresponsive units has shown to be significant in determining the relaxometric behaviour. Previous comparisons of bismacrocyclic Ca-responsive SCAs with either an ethyl or propyl linker between the DO3A MR reporting unit and the EGTA-derived $\mathrm{Ca}^{2+}$ chelator revealed such an effect. ${ }^{16}$ The propyl derivative showed an increased relaxometric enhancement (i.e. increase in longitudinal $r_{1}$ relaxivity in the presence of $\mathrm{Ca}^{2+}$ ) versus the ethyl version with slightly different starting relaxivities and hydration states of the lanthanide complex. A more advanced coordination study with ethyl and propyl linker SCA model compounds demonstrated further the significant impact of the linker distance on the coordination properties of the complex. ${ }^{17}$ Here, it was evaluated that the shorter ethyl linker is likely to be too close to the paramagnetic metal centre hindering the interaction of the carboxylate group with $\mathrm{Gd}^{3+}$.

Recently we reported a study where a series of G4 polyamidoamine (PAMAM) dendrimers conjugated to monomeric SCAs exhibited significant differences in the observed relaxometric properties. Amongst the studied nano-sized conjugates with different monomers, those with butyl and pentyl linkers connecting the common DO3A- and EGTA-derived chelators showed the greatest changes and outlook for potential future application. ${ }^{18}$ Intrigued by these results, we embarked on a detailed structural study of these two newly developed monomeric systems. Firstly, we prepared different pairs of diamagnetic and paramagnetic complexes, which allowed the initiation of different types of coordination chemistry studies. Through the use of a variety of techniques such as 1D and 2D NMR, luminescence lifetime measurements, diffusion ordered NMR spectroscopy (DOSY), density functional theory (DFT) calculations and proton relaxometric titrations, we aimed to characterize the newly developed probes and gain an insight into how subtle structural differences impact on their relaxometric and coordination behaviour.

\section{Results and discussion}

\section{Synthesis and complexation of ligands}

Protected nitro compounds 1 and 2 were synthesized following previously reported procedures. ${ }^{18}$ Subsequent deprotection with formic acid at $60{ }^{\circ} \mathrm{C}$ overnight yielded ligands $\mathbf{L}^{\mathbf{1}}$ and $\mathbf{L}^{2}$ (Scheme 1). Complexation reactions of each ligand with either $\mathrm{Yb}^{3+}, \mathrm{Eu}^{3+}, \mathrm{Gd}^{3+}$ or $\mathrm{Y}^{3+}$ were all carried out under identical conditions. Specifically, the ligands $\mathbf{L}^{\mathbf{1}}$ and $\mathbf{L}^{2}$ were dissolved in water and the $\mathrm{pH}$ adjusted to 7 through the addition of a $0.1 \mathrm{M} \mathrm{NaOH}$ solution. A slight excess of the required lanthanide chloride hydrate was added while maintaining the $\mathrm{pH}$ at 7 through further addition of $0.1 \mathrm{M} \mathrm{NaOH}$. After the final addition, the reaction mixture was stirred overnight at room temperature. The removal of excess lanthanide was achieved by repeated treatment of the solution with Chelex® before filtering and lyophilizing to yield the final complexes, $\mathbf{L n L}^{\mathbf{1}}$ and $\mathbf{L n L}^{2}\left(\mathrm{Ln}=\mathrm{Gd}^{3+}, \mathrm{Yb}^{3+}, \mathrm{Eu}^{3+}\right.$ or $\left.\mathrm{Y}^{3+}\right)$.

\section{Relaxometric titrations}

The relaxometric behaviour of both systems was assessed with proton longitudinal and transverse relaxometric titrations with $\mathbf{G d L}^{\mathbf{1}}$ and $\mathbf{G d L}^{2}$. Each measurement was conducted with an identical initial concentration of $\mathrm{Gd}^{3+}(2.5 \mathrm{mM})$ at $25^{\circ} \mathrm{C}$ and $7 \mathrm{~T}$. The $T_{1}$ and $T_{2}$ relaxation times were recorded and the $r_{1}$ and $r_{2}$ relaxivities were calculated as a function of $\left[\mathrm{Ca}^{2+}\right]$. For $\mathbf{G d L}^{\mathbf{1}}$ with the shorter butyl linker, the starting $r_{1}$ was found to be $2.49 \mathrm{mM}^{-1} \mathrm{~s}^{-1}$, which is slightly lower than that of the propyl derivative and other SCAs developed by us previously (Fig. 1a). ${ }^{13,19}$ Upon saturation with $\mathrm{Ca}^{2+}, r_{1}$ increases to $4.96 \mathrm{mM}^{-1} \mathrm{~s}^{-1}$ (99\% increase). Concurrently, the change in $r_{2}$ over the same $\left[\mathrm{Ca}^{2+}\right]$ range was found to increase to the same
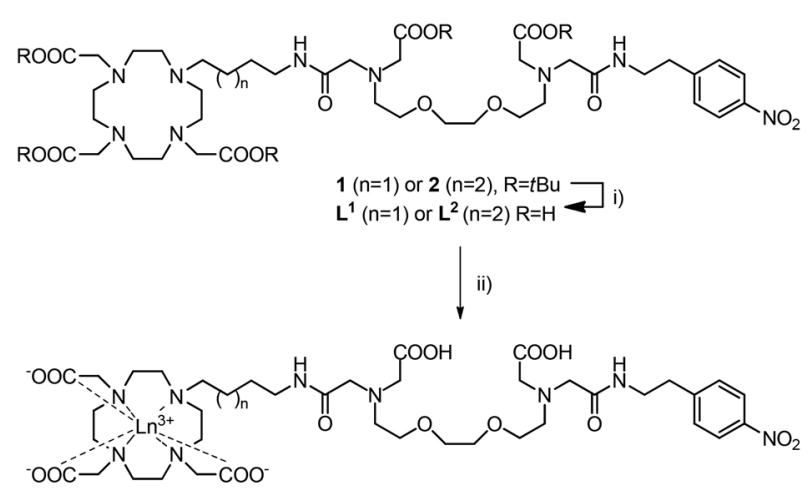

$$
\begin{array}{ll}
\mathbf{G d L}^{1}, \mathrm{n}=1, \mathrm{Ln}=\mathrm{Gd}^{3+} & \mathbf{G d L}^{2}, \mathrm{n}=2, \mathrm{Ln}=\mathrm{Gd}^{3+} \\
\mathrm{YbL}^{1}, \mathrm{n}=1, \mathrm{Ln}=\mathrm{Yb}^{3+} & \mathrm{YbL}^{2}, \mathrm{n}=2, \mathrm{Ln}=\mathrm{Yb}^{3+} \\
\mathrm{EuL}^{1+}, \mathrm{n}=1, \mathrm{Ln}=\mathrm{Eu}^{3+} & \mathrm{EuL}^{2}, \mathrm{n}=2, \mathrm{Ln}=\mathrm{Eu}^{3+} \\
\mathrm{YL}^{1}, \mathrm{n}=1, \mathrm{Ln}=\mathrm{Y}^{3+} & \mathrm{YL}^{2}, \mathrm{n}=2, \mathrm{Ln}=\mathrm{Y}^{3+}
\end{array}
$$

Scheme 1 Synthesis of $\mathrm{L}^{1}, \mathrm{~L}^{2}$ and the subsequent diamagnetic and paramagnetic complexes $\operatorname{LnL}^{1,2}$. Reagents and conditions: (i) $\mathrm{HCO}_{2} \mathrm{H}$, $60^{\circ} \mathrm{C}$. (ii) $\mathrm{LnCl}_{3}$ hydrate, $\mathrm{H}_{2} \mathrm{O}, \mathrm{pH} 7, \mathrm{RT}$, followed by Chelex®, RT. 
a)

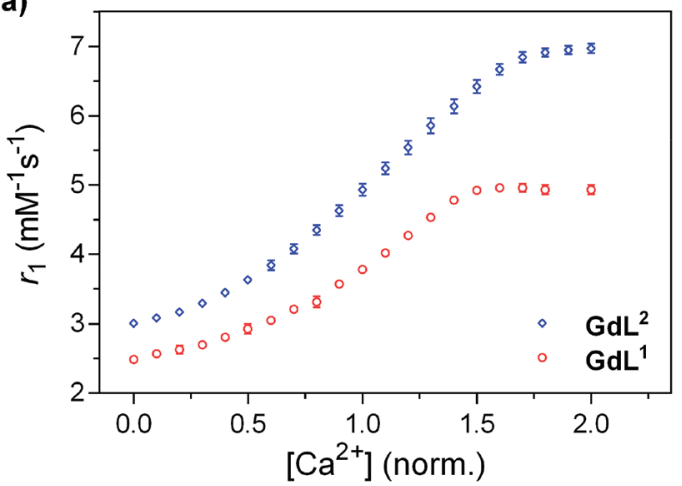

b)

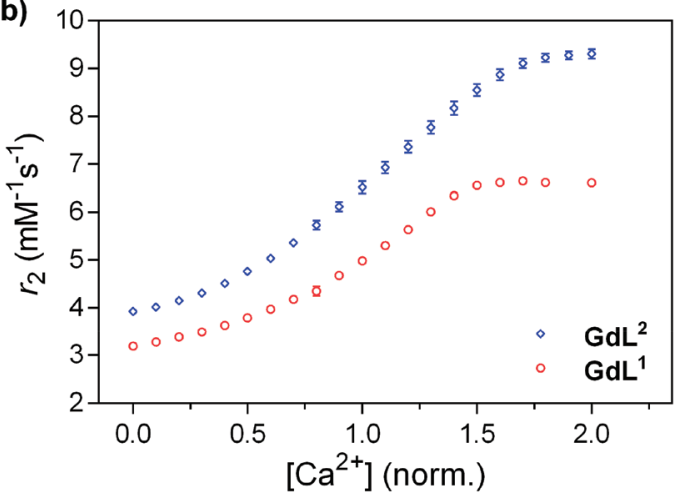

Fig. 1 Relaxometric titration curves for $\mathrm{GdL}^{1}$ and $\mathrm{GdL}^{2}$ with $\mathrm{Ca}^{2+}$ : (a) longitudinal $\left(r_{1}\right)$ and $(\mathrm{b})$ transverse $\left(r_{2}\right)$ titrations. Conditions: $\left[\mathrm{Gd}^{3+}\right]=$ $2.5 \mathrm{mM}, \mathrm{pH}=7.4$ (50 mM HEPES), $25^{\circ} \mathrm{C}, 7 \mathrm{~T}$.

relative extent, specifically from 3.19 to $6.62 \mathrm{mM}^{-1} \mathrm{~s}^{-1}$ (Fig. 1b).

In comparison, $\mathbf{G d L}^{2}$ gave an initial $r_{1}$ of $3.01 \mathrm{mM}^{-1} \mathrm{~s}^{-1}$, which is in line with that of previously investigated SCAs (Fig. 1a). ${ }^{13}$ However, $r_{1}$ reached a value of $6.97 \mathrm{mM}^{-1} \mathrm{~s}^{-1}$ (131\% increase) upon saturation with $\mathrm{Ca}^{2+}$. The change in $r_{2}$ was determined to be from 3.92 to $9.31 \mathrm{mM}^{-1} \mathrm{~s}^{-1}(138 \%$ increase). Concurrently, both $r_{2} / r_{1}$ ratios remained constant at the studied $\mathrm{Ca}^{2+}$ concentrations, indicating that the formation of the Ca-GdL ${ }^{\mathbf{1 , 2}}$ complex is likely not followed by any size changes between the paramagnetic species in the absence and presence of $\mathrm{Ca}^{2+}$ (Fig. S1 in ESI $\dagger$ ). ${ }^{19}$ It can also be observed that the initial relaxivity values in the absence of $\mathrm{Ca}^{2+}$ are lower for $\mathbf{G d L}^{\mathbf{1}}$ than the other complexes studied, indicating a lower hydration state of the complex (see below) and a changed coordination environment of the carboxylate from the EGTA-derived component. Clearly, the linker length between the MR reporting moiety and the bioresponsive unit has significant effects on the relaxometric behaviour of the SCA.

\section{High resolution ${ }^{1} \mathrm{H}$ NMR studies}

In order to understand and observe how the addition of $\mathrm{Ca}^{2+}$ impacts the structure and coordination environment of both derivatives, we conducted a series of high-resolution 1D and 2D NMR experiments at $800 \mathrm{MHz}$. Specifically, a series of diamagnetic and paramagnetic complexes were synthesised and studied at $20 \mathrm{mM}$ concentration and $\mathrm{pD}$ 7.0. ${ }^{1} \mathrm{H}-\mathrm{NMR}, \mathrm{COSY}$ and ${ }^{13} \mathrm{C}$-HSQC of the complexes were recorded, the peaks were assigned and the behaviour of specific groups in the absence and presence of $\mathrm{Ca}^{2+}$ was followed.

We first assigned the relevant peaks that exhibited changes at different conditions (i.e. absence or presence of $\mathrm{Ca}^{2+}$ ), excluding the resonances of the methylene groups neighbouring the amines of the EGTA-derived chelator. These were not observable in the recorded spectra, likely due to exchange processes related to the partial deprotonation of the amine groups at the studied pD. ${ }^{15}$ Furthermore, we noticed that the differences between the two states (without $\mathrm{Ca}^{2+} /$ with $\mathrm{Ca}^{2+}$ ) exist only in the linker between the MR reporting and bioresponsive moiety; hence more detailed analysis followed only for this structural region. The ${ }^{13} \mathrm{C}$-HSQC spectra of the diamagnetic derivatives ( $\mathbf{Y L}^{\mathbf{1}}$ and $\mathbf{Y L}^{\mathbf{2}}$ ) were the most informative, with the obtained results then being compared to the paramagnetic complexes EuL ${ }^{\mathbf{1}, \mathbf{2}}$ and $\mathbf{Y} \mathbf{b L}^{\mathbf{1 , 2}}$. For the butyl derivative, $\mathbf{Y L}^{\mathbf{1}}$, the closest $\left(\mathbf{A}_{\mathbf{1}}\right)$ and furthest $\left(\mathbf{D}_{\mathbf{1}}\right)$ methylene units to the macrocycle ring show a minor shift upon the addition of $\mathrm{Ca}^{2+}$ (Fig. 2). On the other hand, the 'inner' methylene units of the linker ( $\mathbf{B}_{\mathbf{1}}$ and $\mathbf{C}_{\mathbf{1}}$ ) show significant changes upon $\mathrm{Ca}^{2+}$ binding. Moreover, for both groups a single major signal is observable in the unsaturated state, which splits into two clear signals with equal intensity when saturated with $\mathrm{Ca}^{2+}$. Exchanging $\mathrm{Y}^{3+}$ for paramagnetic ions $\left(\mathrm{Eu}^{3+}, \mathrm{Yb}^{3+}\right)$ shows the same trends. This time, the signal splitting for $\mathbf{B}_{\mathbf{1}}$ and $\mathbf{C}_{\mathbf{1}}$ methylene groups upon $\mathrm{Ca}^{2+}$ binding is accompanied with the
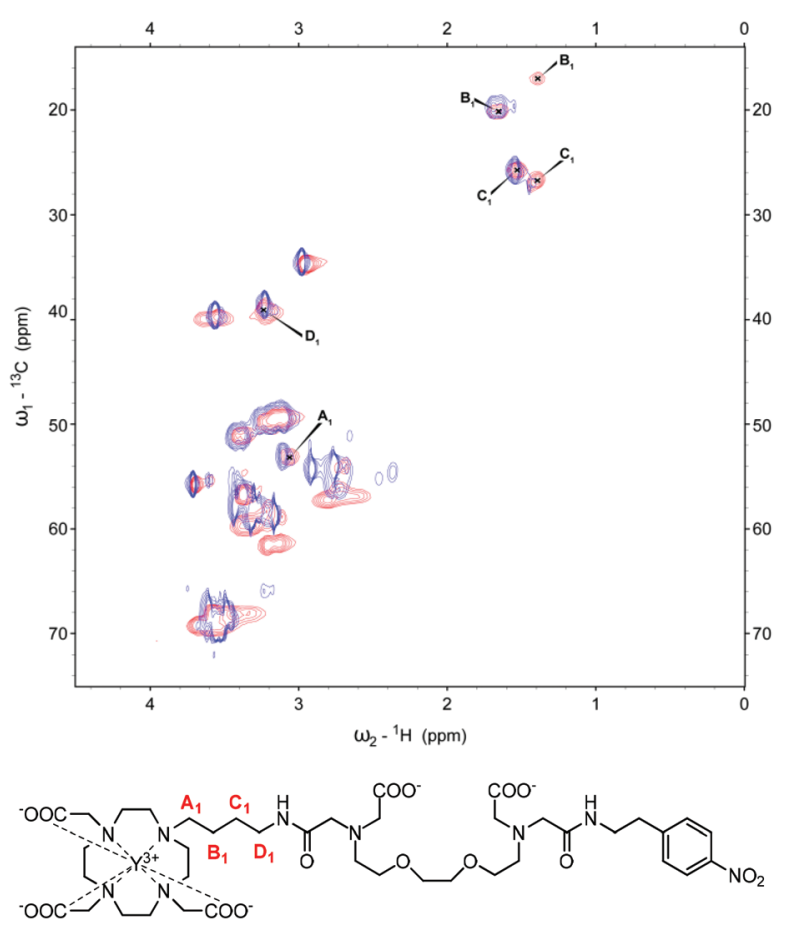

Fig. $2{ }^{13} \mathrm{C}$-HSQC spectrum of $\mathrm{YL}^{1}$ with the signals of interest assigned pre- (blue) and post- $\mathrm{Ca}^{2+}$ (red) addition (top). Chemical structure of $\mathrm{YL}^{1}$ with the methylene units of interest labelled (bottom). 
partial or complete signal loss of the $\mathbf{A}_{\mathbf{1}}$ methylene in $\mathbf{E u L}^{\mathbf{1}}$ and $\mathbf{Y b L}^{\mathbf{1}}$, respectively (Fig. S2 in ESI $\dagger$ ).

Similarly for $\mathbf{Y L}^{2}$, the $\mathrm{CH}_{2}$ unit closest to the macrocyclic ring $\left(\mathbf{A}_{\mathbf{2}}\right)$ shows a minor shift upon the addition of $\mathrm{Ca}^{2+}$ (Fig. 3). Moving further away from the macrocyclic ring, one signal is observable for the $\mathbf{B}_{\mathbf{2}}$ methylene group prior to $\mathrm{Ca}^{2+}$ addition, which then splits to form a new additional signal with lower intensity upon $\mathrm{Ca}^{2+}$ binding. $\mathbf{C}_{2}$ methylene shows similar splitting behaviour to $\mathbf{B}_{2}$ when $\mathrm{Ca}^{2+}$ binds, however both new signals are present with similar intensities. Moving towards the amide unit, the $\mathbf{D}_{\mathbf{2}}$ methylene group initially presents as two spots which then merge towards one with the addition of $\mathrm{Ca}^{2+}$, while the furthest methylene group in the linker, $\mathbf{E}_{2}$, experiences a minor change. As in the case for the complexes with the butyl linker, analysis of paramagnetic complexes reveals loss of the signal for the $\mathbf{A}_{2}$ methylene group in both $\mathbf{E u L}^{2}$ and $\mathbf{Y b L}^{2}$ upon $\mathrm{Ca}^{2+}$ binding (Fig. S2 in ESI $\dagger$ ). Obviously, the difference in the observed spectra of the studied peaks across the metals originates from their different paramagnetic effects. For example, the signals for $\mathbf{A}_{\mathbf{1}} / \mathbf{A}_{\mathbf{2}}$ methylene groups, which are observable in $\mathbf{Y L}^{\mathbf{1 - 2}}$ after the addition of $\mathrm{Ca}^{2+}$, disappear in the cases of $\mathrm{Ca}^{2+}$ addition to $\mathbf{E u L}^{\mathbf{1 - 2}}$ and $\mathbf{Y b L} \mathbf{L}^{\mathbf{1 - 2}}$. We assume that a combination of the paramagnetic relaxation effect (shortening of $T_{1}$ and $T_{2}$ relaxation times) due to the proximity of the $\mathbf{A}_{1} / \mathbf{A}_{2}$ groups to the lanthanide and the increased conformational exchange leads to the overall signal loss that cannot be detected via NMR anymore.
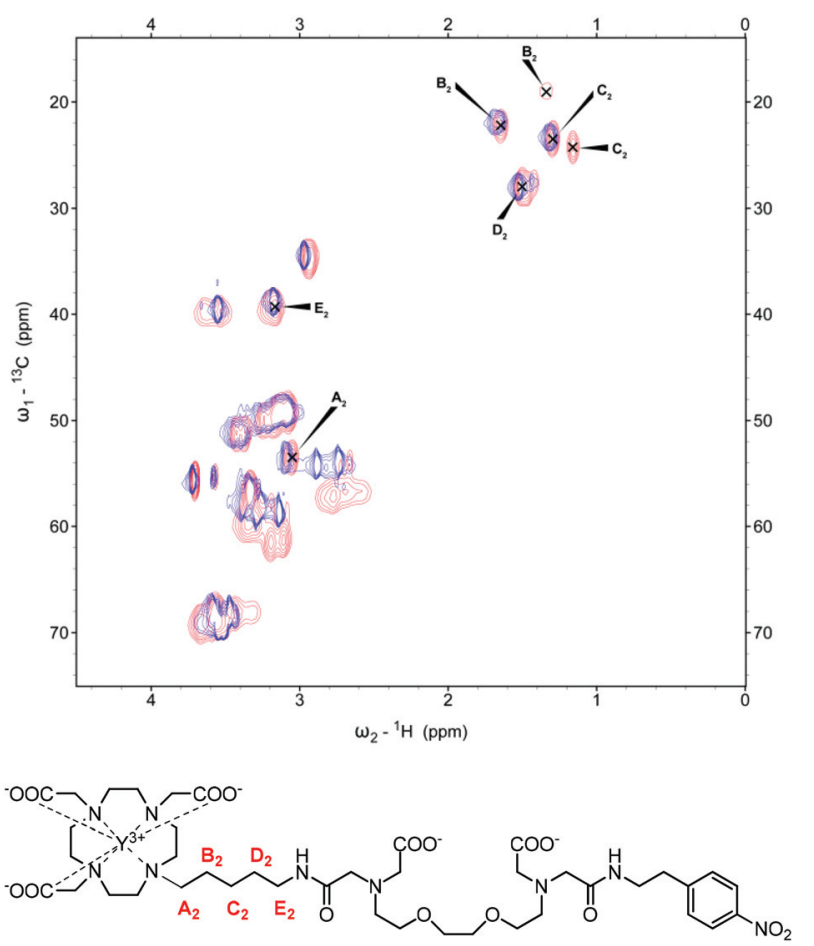

Fig. $3{ }^{13} \mathrm{C}$-HSQC spectrum of $\mathrm{YL}^{2}$ with the signals of interest assigned pre-(blue) and post-Ca ${ }^{2+}$ (red) addition (top). Chemical structure of $\mathrm{YL}^{2}$ with the carbon units of interest labelled (bottom).
More importantly, the signal splitting and shifting of peaks seen in the $\mathbf{B}_{\mathbf{1}, \mathbf{2}}, \mathbf{C}_{\mathbf{1 , 2}}$ and $\mathbf{D}_{\mathbf{2}}$ methylene groups suggest a substantial change in their environment between both the starting and saturated $\mathrm{Ca}^{2+}$ states. As these units are not in direct contact and should not participate directly in the binding of the added $\mathrm{Ca}^{2+}$, the movement of such signals indicates a change in the coordination behaviour of the complex. The mechanism of action for these $\mathrm{Ca}^{2+}$-responsive SCAs has previously been investigated. ${ }^{15}$ Specifically, in the absence of $\mathrm{Ca}^{2+}$, the closest carboxylate of the EGTA-derived moiety binds to the metal centre restricting water access. In the presence of $\mathrm{Ca}^{2+}$, this carboxylate preferentially binds to $\mathrm{Ca}^{2+}$ thus increasing the access of water to the complex. The results obtained here are in line with this theory, as it can be envisaged that the 'off-state' will present in a conformation which can be considered as a ring-like structure through which the EGTAderived carboxylate is coordinated to the lanthanide of the macrocycle. Subsequent $\mathrm{Ca}^{2+}$ addition triggers the breaking of this arrangement due to its higher affinity for $\mathrm{Ca}^{2+} v s . \mathrm{Gd}^{3+}$ to form a new structure/conformation, which is highlighted through the shifting and splitting of signals in the ${ }^{13} \mathrm{C}-\mathrm{HSQC}$ spectra. The observed changes of the signals from the linker methylene units indicate a noteworthy change in the coordination environment around the macrocyclic chelator between the two states and further evidences a conformational change in the responsive mechanism previously described. Moreover, the existence of two signals upon addition of $\mathrm{Ca}^{2+}$ supports the presence of two SAP and TSAP stereoisomers (see below). Since the signals of the $\mathrm{C}=\mathrm{O}$ group of the amide could not be observed in any of the performed NMR experiments, we could not draw any conclusion on its fate, and whether this carbonyl does or does not coordinate to the metal centre. Indeed, the luminescence lifetime experiments revealed values that suggest an equilibrium of non- and mono-hydrated species (see below). Combined with the absence of NMR signals, our findings suggest that the carbonyl interacts with the metal ion throughout in either of the studied conditions (with or without added $\mathrm{Ca}^{2+}$ ).

The ${ }^{1} \mathrm{H}$ NMR spectra of the $\mathbf{E} \mathbf{u L}^{\mathbf{1}}$ and $\mathbf{E u L}^{2}$ complexes show paramagnetically shifted signals in the range $\sim-20$ to $28 \mathrm{ppm}$ (Fig. 4). The signals of the most shifted axial protons are observed between 20 and 28 ppm, a range that is typical of square antiprismatic coordination (SAP) around the metal ion. $^{20-23}$ The signals due to the axial protons of the twisted square antiprismatic (TSAP) isomers are usually observed around 10-15 ppm. The resonances due to the TSAP isomer are barely visible in the case of $\mathbf{E} \mathbf{u L}^{2}$, while for $\mathbf{E} \mathbf{u} \mathbf{L}^{\mathbf{1}}$ the population of the TSAP isomer can be estimated to be $10-15 \%$.

Interestingly, the NMR spectra of the $\mathbf{E u L}^{\mathbf{1}}$ and $\mathbf{E} \mathbf{u} \mathbf{L}^{2}$ complexes are very similar, which indicates that they possess comparable magnetic anisotropies and thus coordination environments around the metal ion. ${ }^{24}$ Furthermore, the spectra are characterised by rather well resolved signals, which indicates fairly rigid conformations in the Ca-free conditions and likely coordination of both the carboxyl group and the amide pendant arm to the metal ion. Indeed, $\mathrm{Eu}^{3+}$ complexes of 


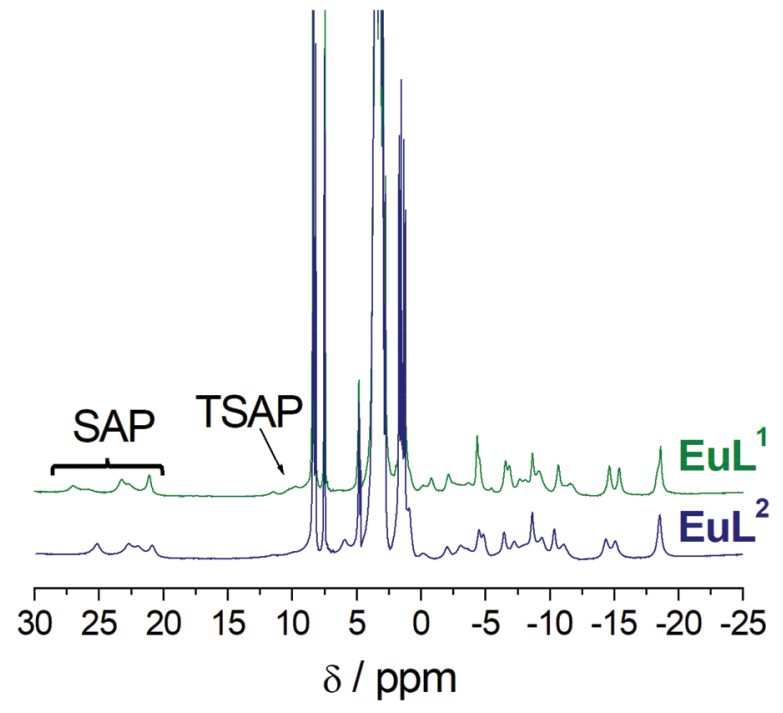

Fig. $4{ }^{1} \mathrm{H}$ NMR spectra of the EuL ${ }^{1}$ and EuL ${ }^{2}$ complexes recorded in $\mathrm{D}_{2} \mathrm{O}$ solution $\left(800 \mathrm{MHz}, 25^{\circ} \mathrm{C}, \mathrm{pD} 7\right)$.

DO3A derivatives generally give ${ }^{1} \mathrm{H}$ NMR spectra with broad signals. $^{25}$ Obviously, the spectra recorded for EuL ${ }^{1-2}$ suggest their atypical coordination mode with the paramagnetic metal ions, which supports the hypothesized existence of the coordination of the carboxyl and amide groups in absence of $\mathrm{Ca}^{2+}$. On the other hand, addition of $\mathrm{Ca}^{2+}$ provokes severe broadening of the ${ }^{1} \mathrm{H}$ NMR resonances. This is in line with a more fluxional behaviour of the macrocyclic ring due to expected decoordination of the carboxylate and possibly partial decoordination or elongation of the coordination bond of the amide group (see below and Fig. S3 in ESI†).

\section{NMR diffusion measurements}

The diffusion of molecules can significantly describe their behaviour in solution and could potentially show any aggregation present. Diffusion coefficients for each derivative was therefore assessed prior to and after the addition of $\mathrm{Ca}^{2+}$ with DOSY on the $\mathbf{E u}^{3+}$ analogues $\left(\mathbf{E} \mathbf{u} \mathbf{L}^{\mathbf{1}}\right.$ and $\left.\mathbf{E} \mathbf{u} \mathbf{L}^{2}\right)$ at three different concentrations $(20,10$ and $5 \mathrm{mM})$. The diffusion coefficients obtained for the two systems studied here were both in agreement with similar monomeric species previously studied (Table 1). ${ }^{19,26}$

Generally, decreasing the complex concentration led to a slight increase in diffusion coefficient which is naturally expected. Additionally, the diffusion of $\mathbf{E u L}^{2}$ was slightly slower than that of $\mathbf{E u L}^{\mathbf{1}}$, which is logical due to the minor difference in their size and greater linker length in $\mathbf{E u L}^{2}$. When comparing samples of identical concentrations upon $\mathrm{Ca}^{2+}$ addition (2 equiv.), similar, or a slight increase in diffusion coefficient was also observed. This is indicative of a change in conformation expected upon $\mathrm{Ca}^{2+}$ binding and faster diffusion of these complexes in solution. These tiny observed changes in diffusion along with the absolute values indicate systems which interact with $\mathrm{Ca}^{2+}$; however, its addition leads to conformational changes that cause slightly faster diffusion of the species in solution for both studied complexes, while likely excluding the formation of aggregates.

\section{Luminescence experiments}

Luminescence emission lifetime and steady-state measurements were performed to assess the hydration states of the complexes and further understand the coordination environment of the lanthanide ion. As previously well established for this class of SCAs, the hydration of the inner sphere of the complex is expected to increase upon addition of the analyte, which is commonly the major cause for the enhancement in the relaxivity. ${ }^{14,27}$ However, the hydration change must not be the sole reason for the relaxivity enhancement, as the intramolecular hydrogen bonding or the deprotonation of proximate amines and the consequent changes in the prototopic exchange may additionally influence the amplitude of the relaxivity changes. ${ }^{17,28}$

Measurements were carried out with the $\mathbf{E u L}^{\mathbf{1 - 2}}(5 \mathrm{mM})$ analogues in both $\mathrm{H}_{2} \mathrm{O}$ and $\mathrm{D}_{2} \mathrm{O}$ and the hydration number $(q)$ was calculated (Table 2) following a previously reported method. ${ }^{29}$ Consequently, the calculated hydration numbers for both $\mathbf{E u L}^{1-2}$ complexes increase upon $\mathrm{Ca}^{2+}$ binding, complimentary to that previously observed with other DO3A-based Ca-responsive SCAs. ${ }^{15,16}$ The length of the linker impacts the initial inner sphere hydration state of the complex. The shorter butyl derivative, $\mathbf{E} \mathbf{u L}^{\mathbf{1}}$, is less hydrated in the initial

Table $2 q$ values calculated for $\mathrm{EuL}^{1-2}$ with and without $\mathrm{Ca}^{2+}$ (2 equiv.)

\begin{tabular}{|c|c|c|c|c|c|c|}
\hline & \multicolumn{3}{|l|}{ No $\mathrm{Ca}^{2+}$} & \multicolumn{3}{|c|}{$+\mathrm{Ca}^{2+}(2$ equiv. $)$} \\
\hline & $\tau_{\mathrm{H}_{2} \mathrm{O}}(\mathrm{ms})$ & $\tau_{\mathrm{D}_{2} \mathrm{O}}(\mathrm{ms})$ & $q$ & $\tau_{\mathrm{H}_{2} \mathrm{O}}(\mathrm{ms})$ & $\tau_{\mathrm{D}_{2} \mathrm{O}}(\mathrm{ms})$ & $q$ \\
\hline EuL $^{1}$ & 0.726 & 1.142 & 0.3 & 0.584 & 1.159 & 0.7 \\
\hline $\mathbf{E u L}^{2}$ & 0.652 & 1.140 & 0.5 & 0.539 & 0.982 & 0.7 \\
\hline
\end{tabular}

Table 1 Diffusion coefficients calculated for $\mathrm{EuL}^{1}$ and $\mathrm{EuL}^{2}$ with and without $\mathrm{Ca}^{2+}$ (2 equiv.)

\begin{tabular}{|c|c|c|c|c|c|c|}
\hline & \multicolumn{6}{|c|}{ Diffusion coefficient $D\left(10^{-10} \mathrm{~m}^{2} \mathrm{~s}^{-1}\right)$} \\
\hline & \multicolumn{3}{|l|}{ No $\mathrm{Ca}^{2+}$} & \multicolumn{3}{|l|}{$+\mathrm{Ca}^{2+}$} \\
\hline & $20 \mathrm{mM}$ & $10 \mathrm{mM}$ & $5 \mathrm{mM}$ & $20 \mathrm{mM}$ & $10 \mathrm{mM}$ & $5 \mathrm{mM}$ \\
\hline EuL $^{1}$ & $1.76 \pm 0.06$ & $1.97 \pm 0.01$ & $1.99 \pm 0.04$ & $1.89 \pm 0.02$ & $2.01 \pm 0.04$ & $2.05 \pm 0.06$ \\
\hline $\mathbf{E u L}^{2}$ & $1.76 \pm 0.02$ & $1.90 \pm 0.04$ & $1.95 \pm 0.04$ & $1.71 \pm 0.01$ & $1.91 \pm 0.01$ & $1.96 \pm 0.02$ \\
\hline
\end{tabular}


state compared to that of $\mathbf{E} \mathbf{u L}^{2}$, which explains the initial $r_{1}$ relaxivity value observed in the relaxometric titrations previously discussed (Fig. 1). The increased initial hydration state of $\mathbf{E} \mathbf{u} \mathbf{L}^{2}$ additionally indicates a lesser interaction between the EGTA-derived carboxylate and $\mathrm{Eu}^{3+}$ compared to $\mathbf{E u L}^{\mathbf{1}}$, possibly resulting from an increased distance between these two moieties. Otherwise, reasons involving an altered conformational arrangement or a change in ratio of the SAP and TSAP isomers could provide possible explanations. The luminescence steady-state emission spectra were in line with the determined $q$ values - the initial emission signal intensity was greater for $\mathbf{E u L}^{\mathbf{1}}$, due to its lower hydration (Fig. S4 in ESI $\dagger$ ); subsequently, the signal intensities for $\mathbf{E u L}^{\mathbf{1}}$ and $\mathbf{E u L}^{\mathbf{2}}$ equalized upon the addition of $\mathrm{Ca}^{2+}$.

\section{DFT studies}

DFT calculations were carried out in an attempt to rationalize the structure of the $\mathbf{G d L}^{\mathbf{1 - 2}}$ complexes and their response to the presence of $\mathrm{Ca}^{2+}$ (see computational details in Experimental section). For the sake of computational simplicity, the structures of the complexes were truncated at the carbon of the ethylene bridge closer to the amide group (Fig. 5 and Fig. S5 in ESI $\dagger$ ). The simplified models will be denoted as

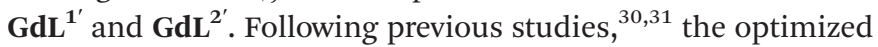
structures of the SAP isomers of $\mathbf{G d L}^{\mathbf{1}^{\prime}-\mathbf{2}^{\prime}}$ included three explicit
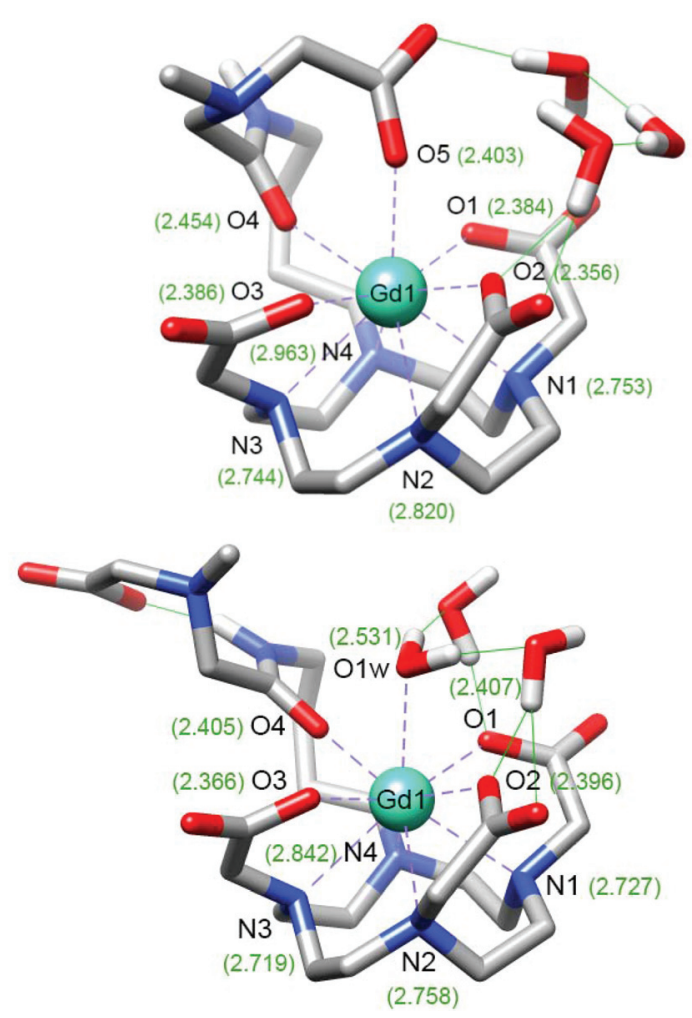

Fig. 5 Optimized structures of the $\mathrm{GdL}^{{ }^{1}}$ system obtained with DFT calculations showing the coordination of the carboxylate group of the side chain (top) or the coordination of a water molecule (bottom). The numbers represent the calculated bond distances $(\AA \AA)$ between the metal centre and the ligand donor atoms. water molecules to improve the description of the $\mathrm{Gd}-\mathrm{O}_{\text {water }}$ bonds. Geometry optimizations provided two energy minima for each complex in which either a water molecule or a carboxylate group is coordinating at the apical position of the SAP coordination polyhedron. Coordination of the amide oxygen atom takes place regardless of the length of the spacer or the concomitant coordination of the acetate group of the EGTA moiety at the apical position. The calculated $\mathrm{Gd}-\mathrm{O}_{\text {amide }}$ distances are 2.405 and $2.418 \AA$ for the monohydrated $(q=1)$ forms of $\mathbf{G d L}^{\mathbf{1}^{\prime}}$ and $\mathbf{G} \mathbf{d} \mathbf{L}^{\mathbf{2}^{\prime}}$, respectively.

Coordination of the carboxylate group at the apical position results in a significant lengthening of the $\mathrm{Gd}-\mathrm{O}_{\text {amide }}$ bonds to 2.454 and $2.492 \AA$ for $\mathbf{G d L}^{\mathbf{1}^{\prime}}$ and $\mathbf{G} \mathbf{d L}^{\mathbf{2}^{\prime}}$, respectively. The longer $\mathrm{Gd}-\mathrm{O}_{\text {amide }}$ distances calculated for the $\mathbf{G d L}^{\mathbf{2}^{\prime}}$ complex reflect a weaker coordination of the amide oxygen atom associated to the longer pentyl spacer. The energy differences between the calculated structures with $q=1$ and $q=0$ favour the apical coordination of the carboxylate group by $\Delta E_{\mathrm{ZPE}}=1.2$ and $0.93 \mathrm{kcal} \mathrm{mol}^{-1}$ for $\mathbf{G d L}^{\mathbf{1}^{\prime}}$ and $\mathbf{G d L}^{\mathbf{2}^{\prime}}$, respectively. The slightly smaller energy difference calculated for $\mathbf{G d L}^{\mathbf{2}^{\prime}}$ suggests that the higher relaxivity observed for $\mathbf{G d L}^{2}$ in the absence of $\mathrm{Ca}^{2+}$ might be related to a higher contribution of the hydrated form of the complex. The DFT results are in line with our previous studies that indicated the coordination of a carboxylate group of the EGTA moiety at the apical position in the absence of $\mathrm{Ca}^{2+}$, resulting in a non-hydrated species. Addition of $\mathrm{Ca}^{2+}$ causes the de-coordination of this group, which gets involved in $\mathrm{Ca}^{2+}$ coordination, yielding a $q=1$ complex. Thus, our DFT results indicate that extending the length of the spacer connecting the DO3A moiety and the amide group, by introducing butyl or pentyl linkers, does not alter the mechanism for $\mathrm{Ca}^{2+}$ response. Our results also support the coordination of the amide group both in the absence and in the presence of $\mathrm{Ca}^{2+}$, in line with the hydration numbers determined from luminescence lifetime measurements, which point to monohydrated complexes after $\mathrm{Ca}^{2+}$ binding. This was also supported in a number of previous studies by ${ }^{17} \mathrm{O}$ NMR measurements, ${ }^{32-34}$ which provided hyperfine coupling constants $A / \hbar$ that confirmed the formation of mono-hydrated species. The higher relaxivities observed for the $\mathrm{Ca}^{2+}$-bound form of $\mathbf{G d L}^{2}$ compared to $\mathbf{G d L}^{\mathbf{1}}$ are therefore not likely related by an increased number of coordinated water molecules, but perhaps to a more important contribution of second-sphere water molecules.

\section{Conclusions}

To conclude, we have designed, synthesised and characterised a new pair of Ca-responsive SCAs with altered linker lengths between the MR reporting and bioresponsive moieties. Relaxometric, NMR, DOSY, luminescence lifetime and DFT studies were performed to analyse and evaluate the coordination behaviour of both systems. Throughout the studies, the sensitivity of such molecules to discrete structural changes is apparent. As the linker length increased, the initial hydration 
state of $\mathbf{E} \mathbf{u L}^{2}$ was observed to be higher than in $\mathbf{E} \mathbf{u} \mathbf{L}^{\mathbf{1}}$, resulting in a greater starting relaxivity. The subsequent change in relaxivity upon $\mathrm{Ca}^{2+}$ addition varied significantly depending on the linker length. Specifically, the overall $r_{1}$ and $r_{2}$ relaxivity change for $\mathbf{G d L}^{2}$ was found to be 131 and $138 \%$ respectively; while for the shorter system, $\mathbf{G d L}^{\mathbf{1}}$, changes of 99 and $107 \%$ were observed for both $r_{1}$ and $r_{2}$ respectively. Results from the DOSY experiments, described a system in which negligible change in the diffusive behaviour of the complex between the initial and $\mathrm{Ca}^{2+}$ saturated states took place. High-resolution NMR studies provided further insights and validations to the responsive mechanism of these types of Ca-responsive probes previously reported. DFT calculations supported the existence of the postulated Ca-triggered coordination changes evidenced in the above described experiments.

Overall, here we have evaluated the coordination properties of two DO3A-based Ca-responsive systems with increased spacer distance and compared them to the previously employed derivatives for their suitability as scaffolds in the future development of Ca-responsive SCAs. The results of this study have provided important information into how subtle structural changes can impact the responsivity of such systems, aiding in the design of future monomeric SCAs in the pursuit of more effective Ca-responsive probes. Moreover, the investigated systems exhibited affirmative relaxometric properties that can be further exploited, making them promising candidates for the preparation and utilisation of multifunctional SCAs for fMRI applications.

\section{Experimental section}

\section{General remarks}

Commercially available reagents and solvents were used without further purification. Compounds $\mathbf{1}$ and 2 were synthesised following published procedures. ${ }^{18}$ High resolution mass spectra were recorded on a Bruker Daltonics APEX II (FT-ICR-MS) with an electrospray ionization source. Low resolution mass spectra were recorded on an Agilent ion trap SL 1100 system with an electrospray ionization source. All NMR, diffusion and relaxometric experiments were performed on Bruker Avance III $300 \mathrm{MHz}$ and Avance III $800 \mathrm{MHz}$ spectrometers at $298 \mathrm{~K}$. Processing was performed using TopSpin 2.1 (Bruker GmbH), ACD/SpecManager 9.0 (Advanced Chemistry Development, Inc.) or Sparky 3.115. The NMR spectra were obtained in $\mathrm{D}_{2} \mathrm{O}$, using the deuterium lock frequency. The concentration of $\mathrm{Gd}^{3+}, \mathrm{Eu}^{3+}$ or $\mathrm{Yb}^{3+}$ in analysed solutions was determined using the bulk magnetic susceptibility shift (BMS). ${ }^{35}$ The luminescence lifetime measurements were performed on a QuantaMaster ${ }^{\mathrm{TM}} 3 \mathrm{PH}$ fluorescence spectrometer from Photon Technology International, Inc. (USA).

\section{Synthetic procedures}

General procedure for ligands $\mathbf{L}^{1}$ and $\mathbf{L}^{2}$. Protected compounds $\mathbf{1}$ or $\mathbf{2}$ were dissolved in formic acid and the mixture was stirred at $60{ }^{\circ} \mathrm{C}$ overnight. The solvent was then removed under reduced pressure and the resulting residue was redissolved in water and lyophilized to give ligands $\mathbf{L}^{\mathbf{1 - 2}}$ which were used without further purification (Fig. S6-8 in ESI $\dagger$ ).

[4,7-Bis-carboxymethyl-10-(4-\{2-[carboxymethyl-(2-\{2-[2-(carboxymethyl-\{[2-(4-nitro-phenyl)-ethylcarbamoyl]-methyl $\}$-amino)ethoxy]-ethoxy\}-ethyl)-amino]-acetylamino\}-butyl)-1,4,7,10 tetraaza-cyclododec-1-yl]-acetic acid ( $\left.\mathbf{L}^{\mathbf{1}}\right) .{ }^{\mathbf{1}} \mathbf{H}$ NMR $\left(300 \mathrm{MHz}, \mathrm{D}_{2} \mathrm{O}\right)$ $\delta$ (ppm): 1.45-1.81 (m, 4H), 2.92 (t, $J=6.2 \mathrm{~Hz}, 2 \mathrm{H}), 2.98-3.94$ (br, 44H), $4.02(\mathrm{~s}, 2 \mathrm{H}), 4.12(\mathrm{~s}, 2 \mathrm{H}), 7.43(\mathrm{~d}, J=8.3 \mathrm{~Hz}, 2 \mathrm{H})$, $8.10(\mathrm{~d}, J=8.3 \mathrm{~Hz}, 2 \mathrm{H}) .{ }^{13} \mathrm{C}$ NMR $\left(75 \mathrm{MHz}, \mathrm{D}_{2} \mathrm{O}\right) \delta(\mathrm{ppm}): 20.7$, 25.5, 34.6, 38.9, 40.1, 48.7, 49.8, 51.1, 53.6, 54.0, 54.9, 55.2, $55.8,56.1,57.0,57.2,64.4,64.6,69.8\left(-\mathrm{CH}_{2}-\right), 123.7,130.1$, 146.3, 147.6 (ArC), 165.0, 165.3, 169.5, 169.7, 170.3, 174.3 $(\mathrm{C}=\mathrm{O})$. ESI-HRMS: $\quad(\mathrm{m} / \mathrm{z}) \quad[\mathrm{M}+\mathrm{Ca}-\mathrm{H}]^{+}$calcd for $\mathrm{C}_{40} \mathrm{H}_{64} \mathrm{CaN}_{9} \mathrm{O}_{16}{ }^{+}$, 966.4091, found: 966.4073.

[4,7-Bis-carboxymethyl-10-(5-\{2-[carboxymethyl-(2- $\{2-[2-($ carboxymethyl-\{[2-(4-nitro-phenyl)-ethylcarbamoyl]-methyl $\}$-amino)ethoxy]-ethoxy\}-ethyl)-amino]-acetylamino\}-pentyl)-1,4,7,10 tetraaza-cyclododec-1-yl]-acetic acid $\left(\mathbf{L}^{2}\right) .{ }^{1} \mathbf{H}$ NMR $\left(300 \mathrm{MHz}, \mathrm{D}_{2} \mathrm{O}\right)$ $\delta$ (ppm): 1.22-1.82 (m, 6H) 2.62-4.20 (br, 50H), 7.44 (d, $J=$ $7.9 \mathrm{~Hz}, 2 \mathrm{H}), 8.12$ (d, $J=7.7 \mathrm{~Hz}, 2 \mathrm{H}) .{ }^{13} \mathrm{C}$ NMR $\left(75 \mathrm{MHz}, \mathrm{D}_{2} \mathrm{O}\right)$ $\delta$ (ppm): 22.6, 23.2, 27.7, 34.6, 39.2, 40.1, 48.5, 49.9, 51.3, 53.8, $54.0,54.9,55.2,55.8,56.0,56.2,57.0,57.2,64.4,64.6,69.8$ $\left(-\mathrm{CH}_{2}-\right)$, 123.7, 130.1, 146.3, 147.6 (ArC), 165.0, 165.1, 169.4, 169.7, 170.1, $174.5(\mathrm{C}=\mathrm{O})$. ESI-HRMS: $(\mathrm{m} / \mathrm{z})[\mathrm{M}-3 \mathrm{H}+\mathrm{Ca}]^{-}$ calcd for $\mathrm{C}_{41} \mathrm{H}_{64} \mathrm{CaN}_{9} \mathrm{O}_{16}{ }^{-}$, 978.4102, found: 978.4113 .

General procedure for the synthesis of $\mathrm{LnL}^{1-2}$ complexes. Ligands $\mathbf{L}^{\mathbf{1}}$ or $\mathbf{L}^{\mathbf{2}}$ were dissolved in water and the $\mathrm{pH}$ adjusted to 7 by addition of a $0.1 \mathrm{M} \mathrm{NaOH}$ solution. A slight excess of lanthanide chloride (1.1 equiv.) was then added portionwise while maintaining the $\mathrm{pH}$ at 7 with $0.1 \mathrm{M} \mathrm{NaOH}$. After the final addition of lanthanide, the reaction was stirred at room temperature overnight. To ensure the removal of excess lanthanide, Chelex® was added to the solution and stirred for $30 \mathrm{~min}$. After this time, the sample was filtered and another portion of Chelex® added to the filtered solution. This was repeated once more (full procedure involved three applications of Chelex®). After the final treatment, the solution was filtered and lyophilised to yield the final complex (Fig. S9-17 in ESI $\dagger$ ).

\section{NMR}

$\mathrm{YL}^{1} .{ }^{1} \mathrm{H}$ NMR (300 MHz, $\left.\mathrm{D}_{2} \mathrm{O}\right): \delta$ (ppm) 1.33-1.83 (br), 2.23-4.08 (br), 7.46 (d), 8.16 (d). ${ }^{13} \mathrm{C}$ NMR (75 MHz, $\mathrm{D}_{2} \mathrm{O}$ ): $\delta(\mathrm{ppm}) 19.7,25.8,34.5,38.5,39.5,46.4$, 46.8, 49.3, 49.5, 49.7, $51.1,51.1,51.2,53.0,54.0,54.3,54.3,54.6,55.2,55.3,55.3$, 55.7, 56.2, 56.8, 57.9, 58.2, 58.3, 58.7, 58.7, 65.7, 65.8, 65.9, 67.9, 68.1, 69.5, $69.5\left(-\mathrm{CH}_{2}-\right), 123.8,130.1,147.7$ (ArC), 171.1, 173.5, 173.6, 173.8, 178.3, $178.5(\mathrm{C}=\mathrm{O})$.

$\mathbf{Y L}^{2} .{ }^{1} \mathbf{H}$ NMR (300 MHz, $\left.\mathrm{D}_{2} \mathrm{O}\right): \delta$ (ppm) 0.95-1.93 (br), 2.22-4.30 (br), 7.45 (d), 8.15 (d). ${ }^{13} \mathrm{C}$ NMR (75 MHz, $\mathrm{D}_{2} \mathrm{O}$ ): $\delta(\mathrm{ppm}) 21.9,23.3,28.0,34.5,38.7,39.5,49.2,49.2$, 49.7, 49.9, 51.2 , 51.2, 53.5, 54.0, 54.3, 55.3, 55.6, 56.7, 58.0, 58.2, 58.7, $58.7,67.9,68.2,68.5,69.5,69.5\left(-\mathrm{CH}_{2}-\right), 123.7,130.0,147.7$ (ArC), 170.7, 173.2, 173.3, 173.6, 173.7, 177.6, 178.1, 178.3 $(\mathrm{C}=\mathrm{O})$. 


\section{ESI-LRMS}

GdL ${ }^{1} .(m / z)[\mathrm{M}-\mathrm{H}]^{-}$calcd for $\mathrm{C}_{40} \mathrm{H}_{61} \mathrm{GdN}_{9} \mathrm{O}_{16}{ }^{-}$, 1081.3, found: 1081.3. $[\mathrm{M}+\mathrm{Na}-2 \mathrm{H}]^{-}$calcd for $\mathrm{C}_{40} \mathrm{H}_{60} \mathrm{GdN}_{9} \mathrm{NaO}_{16}{ }^{-}$, 1103.3, found: 1103.3 .

EuL ${ }^{1}$. $(m / z)[\mathrm{M}-\mathrm{H}]^{-}$calcd for $\mathrm{C}_{40} \mathrm{H}_{61} \mathrm{EuN}_{9} \mathrm{O}_{16}{ }^{-}$, 1076.3, found: 1076.3. $[\mathrm{M}+\mathrm{Na}-2 \mathrm{H}]^{-}$calcd for $\mathrm{C}_{40} \mathrm{H}_{60} \mathrm{EuN}_{9} \mathrm{NaO}_{16}{ }^{-}$, 1098.3, found: 1098.3 .

YbL ${ }^{1} .(m / z)[\mathrm{M}-\mathrm{H}]^{-}$calcd for $\mathrm{C}_{40} \mathrm{H}_{61} \mathrm{YbN}_{9} \mathrm{O}_{16}{ }^{-}$, 1097.4, found: 1097.3. $[\mathrm{M}+\mathrm{Na}-2 \mathrm{H}]^{-}$calcd for $\mathrm{C}_{40} \mathrm{H}_{60} \mathrm{YbN}_{9} \mathrm{NaO}_{16}{ }^{-}$, 1119.3, found: 1119.3 .

$\mathbf{Y L}^{\mathbf{1}}$. $(m / z)[\mathrm{M}-\mathrm{H}]^{-}$calcd for $\mathrm{C}_{40} \mathrm{H}_{61} \mathrm{YN}_{9} \mathrm{O}_{16}{ }^{-}$, 1012.3, found: 1012.4. $[\mathrm{M}+\mathrm{Na}-2 \mathrm{H}]^{-}$calcd for $\mathrm{C}_{40} \mathrm{H}_{60} \mathrm{YN}_{9} \mathrm{NaO}_{16}{ }^{-}$, 1034.3, found: 1034.3 .

$\mathbf{G d L}^{2}$. $(\mathrm{m} / \mathrm{z})[\mathrm{M}-\mathrm{H}]^{-}$calcd for $\mathrm{C}_{41} \mathrm{H}_{63} \mathrm{GdN}_{9} \mathrm{O}_{16}{ }^{-}$, 1095.4, found: 1095.4. $[\mathrm{M}+\mathrm{Na}-2 \mathrm{H}]^{-}$calcd for $\mathrm{C}_{41} \mathrm{H}_{62} \mathrm{GdN}_{9} \mathrm{NaO}_{16}{ }^{-}$, 1117.4, found: 1117.3 .

EuL ${ }^{2} .(m / z)[\mathrm{M}-\mathrm{H}]^{-}$calcd for $\mathrm{C}_{41} \mathrm{H}_{63} \mathrm{EuN}_{9} \mathrm{O}_{16}{ }^{-}$, 1090.4, found: 1090.4. $[\mathrm{M}+\mathrm{Na}-2 \mathrm{H}]^{-}$calcd for $\mathrm{C}_{41} \mathrm{H}_{62} \mathrm{EuN}_{9} \mathrm{NaO}_{16}{ }^{-}$, 1112.3, found: 1112.3 .

YbL ${ }^{2} .(m / z)[\mathrm{M}-\mathrm{H}]^{-}$calcd for $\mathrm{C}_{41} \mathrm{H}_{63} \mathrm{YbN}_{9} \mathrm{O}_{16}{ }^{-}$, 1111.4, found: 1111.4. $[\mathrm{M}+\mathrm{Na}-2 \mathrm{H}]^{-}$calcd for $\mathrm{C}_{41} \mathrm{H}_{62} \mathrm{YbN}_{9} \mathrm{NaO}_{16}{ }^{-}$, 1133.4, found: 1133.3

$\mathbf{Y L}^{2}$. $(m / z)[\mathrm{M}-\mathrm{H}]^{-}$calcd for $\mathrm{C}_{41} \mathrm{H}_{63} \mathrm{YN}_{9} \mathrm{O}_{16}{ }^{-}$, 1026.3, found: 1026.3. $[\mathrm{M}+\mathrm{Na}-2 \mathrm{H}]^{-}$calcd for $\mathrm{C}_{41} \mathrm{H}_{62} \mathrm{YN}_{9} \mathrm{NaO}_{16}{ }^{-}$, 1048.3, found: 1048.3 .

\section{Relaxometric titrations}

Proton longitudinal and transverse relaxometric titrations with $\mathrm{Ca}^{2+}$ were performed at $7.0 \mathrm{~T}, 298 \mathrm{~K}$ and $\mathrm{pH} 7.4(50 \mathrm{mM}$ HEPES buffer) using inversion recovery $\left(T_{1}\right)$ and Car-PurcellMeiboom-Gill $\left(T_{2}\right)$ pulse sequences. To a solution of $\mathbf{G d L}^{\mathbf{1 - 2}}$ (2.5 $\mathrm{mM})$, a $\mathrm{CaCl}_{2}$ solution of known concentration was added stepwise and $T_{1}$ and $T_{2}$ measurements were performed after each addition. The longitudinal and transverse relaxivities, $r_{1}$ and $r_{2}$, were then calculated using eqn (1), where $T_{1, \mathrm{obs}}$ is the measured $T_{1}(i=1)$ or $T_{2}(i=2), T_{i, \mathrm{~d}}$ is the diamagnetic contribution from the solvent and [Gd] is the actual concentration of $\mathrm{Gd}^{3+}$. A total of three independent measurements were recorded for each $\mathrm{Gd}^{3+}$ complex and the results averaged at each point for the titration to give the final relaxivity values.

$$
\frac{1}{T_{i, \mathrm{obs}}}=T_{i, \mathrm{~d}}+r_{i} \times[\mathrm{Gd}] .
$$

\section{High resolution NMR experiments}

All high resolution NMR spectra were acquired on Bruker AVIII-800 spectrometer, processed with TopSpin 2.1 (Bruker $\mathrm{GmbH}$ ), and analyzed with Sparky $3.115 .{ }^{36}$ For every sample (20 mM $\left.\left[\mathrm{Ln}^{3+}\right]\right), \mathrm{a}^{1} \mathrm{H}-\mathrm{NMR}$ spectra was measured, as well as a DQF-COSY and a ${ }^{13}$ C-HSQC. A standard DQF-COSY ${ }^{37}$ was acquired with 4096 and 128 complex points in $t_{2}$ and $t_{1}$, respectively, performing 256 scans per increment.

The ${ }^{13} \mathrm{C}$-HSQC was recorded at a resolution of $1024\left(t_{2}\right) \times$ $128\left(t_{1}\right)$ complex points, using 64 scans per increment. All experiments were recorded at $298 \mathrm{~K}$, using a relaxation delay of $1.5 \mathrm{~s}$. The water suppression was achieved via pre-saturation for the ${ }^{1} \mathrm{H}$-NMR and the COSY, while the ${ }^{13} \mathrm{C}$-HSQC uses gradient selection (echo/anti-echo).

\section{NMR diffusion measurements}

Samples of $\mathbf{E u L}^{\mathbf{1 - 2}}$ with and without $\mathrm{Ca}^{2+}$ (2 equiv.) were dissolved in $\mathrm{D}_{2} \mathrm{O}$ and the $\mathrm{pD}$ adjusted to 7.0. Diffusion coefficient determination was performed using 2D - Diffusion Ordered NMR Spectroscopy (DOSY). Measurements were performed at $298 \mathrm{~K}$ with 20,10 and $5 \mathrm{mM}\left[\mathrm{Eu}^{3+}\right]$ samples $(\delta \mathrm{t}=2 \mathrm{~ms}, \Delta T=$ $250 \mathrm{~ms}$ ). Data analysis was conducted with TopSpin 2.1 using 16 linear points with a 5-95\% gradient strength. The diffusion coefficients were calculated through the analysis of individual peaks in the aromatic region. Each peak used in the determination provided the diffusion coefficient that was within an error of $0.05 \times 10^{-10} \mathrm{~m}^{2} \mathrm{~s}^{-1}$. The reported diffusion coefficients in Table 1 are the averages of each of the peaks from the three independent measurements with their standard deviation.

\section{Luminescence lifetime measurements}

Luminescence lifetime measurements were performed with EuL ${ }^{1-2}$ at $5 \mathrm{mM}\left[\mathrm{Eu}^{3+}\right]$ in $\mathrm{D}_{2} \mathrm{O}$ and $\mathrm{H}_{2} \mathrm{O}$ with and without $\mathrm{Ca}^{2+}$ (2 equiv.) (298 K, pH 7.4, HEPES). The $\mathrm{Eu}^{3+}$ ion was directly excited and the emission intensity was recorded with a $10 \mu \mathrm{s}$ resolution. The excitation and emission slits were set at $5 \mathrm{~nm}$. In total, three independent measurements each with 25 scans were performed to obtain the data set. The obtained curves were fitted with a first order exponential decay with an $r^{2}=0.99$. The resulting $q$ values were then calculated using eqn (2).

$$
q=1.2 \times\left(\tau_{\mathrm{H}_{2} \mathrm{O}}{ }^{-1}-\tau_{\mathrm{D}_{2} \mathrm{O}}{ }^{-1}-0.25\right) .
$$

DFT computational details. The DFT study presented in this work was performed employing the hybrid meta generalized gradient approximation (hybrid meta-GGA), with the TPSSh exchange-correlation functional ${ }^{38}$ and the Gaussian $09^{39}$ program package. The large-core approximation with the quasirelativistic effective core potential proposed by Dolg et $a{ }^{40}{ }^{40}$ and the associated [5s4p3d]-GTO valence basis set was used for Gd, while the standard 6-31G(d,p) basis set was used for all other atoms. Solvent effects were included by using the integral equation formalism variant of the polarizable continuum model (IEFPCM), ${ }^{41}$ with solute cavities defined by the universal force field (UFF) ${ }^{42}$ radii scaled by a factor of 1.1. Calculations of analytical second derivatives were used to confirm that the optimized geometries correspond to local energy minima on the potential energy surface and to estimate the zero point energies (ZPE).

\section{Conflicts of interest}

There are no conflicts to declare. 


\section{Acknowledgements}

The authors thank Dr Giuseppe Gambino for helpful discussions. The financial support of German Research Foundation (DFG, grant AN 716/7-1) is gratefully acknowledged. C. P.-I. thanks Centro de Supercomputación de Galicia (CESGA) for providing the supercomputer facilities. This work was carried out within the framework of the COST CA15209 Action "European Network on NMR Relaxometry". Open Access funding provided by the Max Planck Society.

\section{Notes and references}

1 D. V. Hingorani, A. S. Bernstein and M. D. Pagel, Contrast Media Mol. Imaging, 2015, 10, 245-265.

2 M. Carril, J. Mater. Chem. B, 2017, 5, 4332-4347.

3 M. C. Heffern, L. M. Matosziuk and T. J. Meade, Chem. Rev., 2014, 114, 4496-4539.

4 G. L. Davies, I. Kramberger and J. J. Davis, Chem. Commun., 2013, 49, 9704-9721.

5 C. S. Bonnet and E. Toth, Chimia, 2016, 70, 102-108.

6 D. Parrott, W. S. Fernando and A. F. Martins, Inorganics, 2019, 7, 18.

7 J. Wahsner, E. M. Gale, A. Rodríguez-Rodríguez and P. Caravan, Chem. Rev., 2019, 119, 957-1057.

8 C. Grienberger and A. Konnerth, Neuron, 2012, 73, 862885.

9 G. W. Zamponi, ACS Chem. Neurosci., 2017, 8, 2583-2585.

10 G. G. Somjen, Ions in the brain: normal function, seizures, and strokes, Oxford University Press, New York, Oxford, 2004.

11 I. Dal Pra, A. Chiarini, R. Pacchiana, E. Gardenal, B. Chakravarthy, J. F. Whitfield and U. Armato, Curr. Neuropharmacol., 2014, 12, 353-364.

12 E. L. Que and C. J. Chang, Chem. Soc. Rev., 2010, 39, 51-60.

13 G. Angelovski, Acc. Chem. Res., 2017, 50, 2215-2224.

14 J. L. Major, R. M. Boiteau and T. J. Meade, Inorg. Chem., 2008, 47, 10788-10795.

15 P. Kadjane, C. Platas-Iglesias, P. Boehm-Sturm, V. Truffault, G. E. Hagberg, M. Hoehn, N. K. Logothetis and G. Angelovski, Chem. - Eur. J., 2014, 20, 7351-7362.

16 G. Angelovski, P. Fouskova, I. Mamedov, S. Canals, E. Toth and N. K. Logothetis, ChemBioChem, 2008, 9, 1729-1734.

17 S. Gündüz, S. Vibhute, R. Botár, F. K. Kálmán, I. Tóth, G. Tircsó, M. Regueiro-Figueroa, D. Esteban-Gómez, C. Platas-Iglesias and G. Angelovski, Inorg. Chem., 2018, 57, 5973-5986.

18 L. Connah and G. Angelovski, Biomacromolecules, 2018, 19, 4668-4676.

19 S. Gündüz, T. Savić, R. Pohmann, N. K. Logothetis, K. Scheffler and G. Angelovski, ACS Sens., 2016, 1, 483-487.

20 C. Kumas, W. S. Fernando, P. Y. Zhao, M. RegueiroFigueroa, G. E. Kiefer, A. F. Martins, C. Platas-Iglesias and A. D. Sherry, Inorg. Chem., 2016, 55, 9297-9305.
21 T. Mani, G. Tircso, O. Togao, P. Zhao, T. C. Soesbe, M. Takahashi and A. D. Sherry, Contrast Media Mol. Imaging, 2009, 4, 183-191.

22 C. M. Fisher, E. Fuller, B. P. Burke, V. Mogilireddy, S. J. A. Pope, A. E. Sparke, I. Dechamps-Olivier, C. Cadiou, F. Chuburu, S. Faulkner and S. J. Archibald, Dalton Trans., 2014, 43, 9567-9578.

23 T. Mani, A. C. L. Opina, P. Y. Zhao, O. M. Evbuomwan, N. Milburn, G. Tircso, C. Kumas and A. D. Sherry, J. Biol. Inorg. Chem., 2014, 19, 161-171.

24 A. W. J. Poh, J. A. Aguilar, A. M. Kenwright, K. Mason and D. Parker, Chem. - Eur. J., 2018, 24, 16170-16175.

25 O. A. Blackburn, M. Tropiano, L. S. Natrajan, A. M. Kenwright and S. Faulkner, Chem. Commun., 2016, 52, 6111-6114.

26 J. Henig, I. Mamedov, P. Fouskova, E. Tóth, N. K. Logothetis, G. Angelovski and H. A. Mayer, Inorg. Chem., 2011, 50, 6472-6481.

27 W. H. Li, G. Parigi, M. Fragai, C. Luchinat and T. J. Meade, Inorg. Chem., 2002, 41, 4018-4024.

28 E. Boros, R. Srinivas, H. K. Kim, A. M. Raitsimring, A. V. Astashkin, O. G. Poluektov, J. Niklas, A. D. Horning, B. Tidor and P. Caravan, Angew. Chem., Int. Ed., 2017, 56, 5603-5606.

29 A. Beeby, I. M. Clarkson, R. S. Dickins, S. Faulkner, D. Parker, L. Royle, A. S. de Sousa, J. A. G. Williams and M. Woods, J. Chem. Soc., Perkin Trans. 2, 1999, 493-503.

30 D. Esteban-Gomez, A. de Blas, T. Rodriguez-Blas, L. Helm and C. Platas-Iglesias, ChemPhysChem, 2012, 13, 36403650 .

31 M. Regueiro-Figueroa and C. Platas-Iglesias, J. Phys. Chem. A, 2015, 119, 6436-6445.

32 K. D. Verma, A. Forgács, H. Uh, M. Beyerlein, M. E. Maier, S. Petoud, M. Botta and N. K. Logothetis, Chem. - Eur. J., 2013, 19, 18011-18026.

33 F. Oukhatar, H. Meudal, C. Landon, N. K. Logothetis, C. Platas-Iglesias, G. Angelovski and É. Tóth, Chem. - Eur. J., 2015, 21, 11226-11237.

34 F. Oukhatar, S. V. Eliseeva, C. S. Bonnet, M. Placidi, N. K. Logothetis, S. Petoud, G. Angelovski and É. Tóth, Inorg. Chem., 2019, DOI: 10.1021/acs.inorgchem.1029b00887.

35 D. M. Corsi, C. Platas-Iglesias, H. van Bekkum and J. A. Peters, Magn. Reson. Chem., 2001, 39, 723-726.

36 T. D. Goddard and D. G. Kneller, SPARKY 3, University of California, San Francisco, ver.

37 A. E. Derome and M. P. Williamson, J. Magn. Reson., 1990, 88, 177-185.

38 J. M. Tao, J. P. Perdew, V. N. Staroverov and G. E. Scuseria, Phys. Rev. Lett., 2003, 91, 146401.

39 Gaussian 09, Revision B.01, Gaussian, Inc., Wallingford CT, ver., 2009.

40 M. Dolg, H. Stoll, A. Savin and H. Preuss, Theor. Chim. Acta, 1989, 75, 173-194.

41 J. Tomasi, B. Mennucci and R. Cammi, Chem. Rev., 2005, 105, 2999-3093.

42 A. K. Rappe, C. J. Casewit, K. S. Colwell, W. A. Goddard and W. M. Skiff, J. Am. Chem. Soc., 1992, 114, 10024-10035. 